\title{
In vitro chromosomal radiosensitivity in patients with common variable immunodeficiency
}

\author{
MAJID MAHMOODI I,2 HASSAN ABOLHASSANI ${ }^{2}$, HOSSEIN MOZDARANI ${ }^{3}$, NIMA REZAEI ${ }^{2}$, \\ GHOLAMREZA AZIZI ${ }^{4}$, REZA YAZDANI ${ }^{2}$, FARIDEH FARZANFAR ${ }^{l}$, HOSEIN RAFIEMANESH ${ }^{5}$, \\ MOHAMMAD-ALI MOHAGHEGHI ${ }^{1}$, KOUROS DIVSALAR ${ }^{6}$, RASOUL NASIRI KALMARZI ${ }^{2}$, \\ ASGHAR RAMYAR ${ }^{2}$, ASGHAR AGHAMOHAMMADI
}

${ }^{1}$ Cancer Research Center, Cancer Institute, Tehran University of Medical Sciences, Tehran, Iran

${ }^{2}$ Research Center for Immunodeficiencies, Pediatrics Center of Excellence, Children's Medical Center Hospital, Tehran University of Medical Sciences, Tehran, Iran

${ }^{3}$ Department of Medical Genetics, Faculty of Medical Sciences, Tarbiat Modares University, Tehran, Iran

${ }^{4}$ Non-Communicable Diseases Research Center, Alborz University of Medical Sciences, Karaj, Iran

${ }^{5}$ Student Research Committee, School of Public Health, Shahid Beheshti University of Medical Sciences, Tehran, Iran

${ }^{6}$ Neuroscience Research Center, Institute of Neuropharmacology, Kerman University of Medical Sciences, Kerman, Iran

\begin{abstract}
Common variable immunodeficiency (CVID) is one of the predominant antibody deficiency disorders, some evidence of which indicates that chromosome instability is present in these patients. An increased risk of cancer in patients with CVID has been documented. This study was undertaken to highlight radiation sensitivity in CVID patients and to clarify the genetic basis of this defect in these cases. Stimulated lymphocytes of the studied subjects were exposed to low-dose gamma-rays in the G2 phase or the G0 phase of the cell cycle and chromosomal aberrations were scored. Lymphocytes of healthy individuals, ataxia telangiectasia (AT) cases and a group of acute lymphoblastic leukemia (ALL) patients were investigated in the same way as controls. By two methods of analysis (one-way ANOVA and unpaired t-test), the CVID cases were significantly more radiosensitive than healthy controls based on the results of the G2 and the GO assays. First-degree relatives of CVID patients were radiosensitive by the micronucleus assay which showed a significant difference as compared with normal controls $(p=0.001)$. In conclusion, this study may support that chromosomal radiosensitivity in CVID patients is a marker of genetic predisposition to the disease. The results might be a clue to describe the increased risk of cancer in CVID patients.
\end{abstract}

Key words: primary immunodeficiency, common variable immunodeficiency, chromosome radiosensitivity, acute lymphoblastic leukemia, ataxia telangiectasia.

(Centr Eur J Immunol 2018; 43 (2): 155-161)

\section{Introduction}

Common variable immunodeficiency (CVID) constitutes the largest group of primary hypogammaglobulinemias [1, 2], manifested by low levels of serum immunoglobulins (Igs) and a wide variety of clinical signs and symptoms such as chronic and recurrent infections (mainly occurring in the respiratory and gastrointestinal tracts), autoimmune diseases and granulomatous lesions [3-7]. CVID patients also are at increased risk of different types of lymphoid malignancies $[2,5]$. The malignancy phenotype in
CVID patients may associate with a state of immune deregulation characterized by various functional abnormalities of both B cells and T cells [8, 9]. Furthermore, impaired cellular immune response such as a decreased number and proportion of different lymphocyte populations, non-responsiveness of lymphocytes to mitogens and antigens, altered levels of cytokine production, and deficient expression of cell-surface molecules may be present in CVID patients [10]. The higher incidence of cancer in CVID cases has also

Correspondence: Asghar Aghamohammadi, MD, PhD, Research Center for Immunodeficiencies, Pediatrics Center of Excellence, Children's Medical Center Hospital, Tehran University of Medical Sciences, 62 Qarib St., Keshavarz Blvd., Tehran 14194, Iran, e-mail: aghamohammadi@sina.tums.ac.ir Submitted: 1.10.2016; Accepted: 5.12.2016 
been explained by genomic instability, manifested by an increased level of chromosomal damage after suitable mutagenic stress in vitro $[11,12]$.

Acute lymphoblastic leukemia (ALL), as a cancer disorder, is known by clonal proliferation, decreased apoptosis and accumulation of immature lymphoid cells, which is arrested at various differentiation stages within the bone marrow and lymphoid tissues [13, 14]. These patients usually have high white blood cell counts and may present with organomegaly, particularly mediastinal lymph nodes enlargement and central nervous system involvement [15]. Since chromosomal defects and molecular abnormalities in ALL patients have been identified [16], we considered ALL patients as a control group to compare radiation-induced chromosomal damage in CVID patients with ALL cases.

This study was carried out to explore radiation sensitivity in CVID patients and their first-degree relatives. This might elucidate the genetic basis of this primary immunodeficiency in these cases.

\section{Material and methods}

\section{Study subjects}

The study population consisted of 30 CVID patients registered in the Children's Medical Center Hospital affiliated by the Tehran University of Medical Sciences, which serves as a referral center for both adult and pediatric patients with primary immunodeficiency diseases in Iran [17, 18]. The study was performed between January 2007 and October 2011. Diagnosis of CVID was based on the criteria of the European Society for Immunodeficiency (ESID) and the Pan-American Group for Immunodeficiency (PAGID) in patients older than 4 years including decreases in serum IgG, IgA, and/or IgM levels by 2 or more standard deviations from the mean and absence of other well-defined antibody deficiencies $[19,20]$. These patients were selected from all available CVID patients according to inclusion criteria including receiving regular intravenous immunoglobulin (IVIG) monthly and no history of smoking and alcohol exposure. Thirty age- and sex- matched healthy individuals served as negative controls, 24 first-degree relatives of CVID patients and 20 ALL patients were also recruited in this study. Moreover, samples obtained from six confirmed ataxia telangiectasia cases by mutation analysis were used as positive controls. Radiosensitivity is a major hallmark of the AT patients [21]. The process of this study was approved by the ethical committee of the Tehran University of Medical Sciences and all patients or their parents or legal guardians were asked to fill an informed consent form.

\section{Cytogenetic methods}

Experimental protocol for the $\mathrm{G}_{2}$ assay: $\mathrm{G}_{2}$ chromosomal radiosensitivity assay was performed essentially as described by Scott et al. [22] with a minor modification.
Prior to culturing, heparinized blood samples from all participants were kept within 4 hours at ambient temperature. For each blood sample, two tissue culture flasks were set up: one for in vitro $\gamma$-irradiation, the other served as control (un-irradiated) for analysis of the spontaneous chromosomal aberrations. To each flask, $0.5 \mathrm{ml}$ of the blood was added in 4.5 RPMI-1640 culture medium supplemented with $10 \%$ fetal calf serum, $1 \% \mathrm{~L}$-glutamine, $100 \mathrm{U} / \mathrm{ml}$ penicillin and $100 \mu \mathrm{g} / \mathrm{ml}$ streptomycin. Phytohemagglutinin or PHA (Life Technologies GmbH, Frankfurt, Germany) at a final concentration of $1 \mu \mathrm{g} / \mathrm{ml}$ was used to induce lymphocyte proliferation. The flasks were incubated in a humidified air atmosphere at $37^{\circ} \mathrm{C}$ with $5 \% \mathrm{CO}_{2}$ for 4 days. Four hours before harvesting, the cultures were exposed to gamma irradiation (Theratron 780e, MDS, Canada; ${ }^{60} \mathrm{Co}, 70 \mathrm{cGy} / \mathrm{min}$ ) with a dose of $100 \mathrm{cGy}$ at ambient temperature. After 2-hour incubation, colcemid (Gibco, final concentration $0.15 \mu \mathrm{g} / \mathrm{ml}$ in the medium) was added to arrest the cells at metaphase. Material of each flask was transferred to a centrifuge tube, and then centrifuged at 1200 RPM for 10 minutes to harvest lymphocytes. The supernatant was then removed and cells were treated with $5 \mathrm{ml}$ of $0.075 \mathrm{M} \mathrm{KCl}$ for 15 minutes. After further centrifugation, the $\mathrm{KCl}$ was removed and the cell suspensions were fixed with fresh fixative (methanol/ glacial acetic acid; $3 / 1$ ) and this process was performed two more times. The cells in suspension were dropped on to clean coded slides. The slides were dried in air and stained with $2 \%$ Giemsa (in phosphate buffer saline, $\mathrm{pH} 7.0$ ) for 5 minutes. Duplicate slides were made for each sample. For structural chromosome aberration study, 100 well-spread metaphases of both irradiated and non-irradiated samples were scanned and scored for aberrations such as chromatid breaks, gaps and exchanges, and chromosome breaks and fragments (Fig. 1). Two genetic experts scored each slide to eliminate scorer bias.

\section{Experimental protocol for G0-micronucleus assay}

Full details are given elsewhere [23], briefly, two tissue culture flasks were prepared and set based on a previous explained method of $\mathrm{G}_{2}$ assay. One of the flasks of each donor was exposed to gamma rays uniformly, total dose of 300 cGy (Theratron 780e, MDS, Canada; ${ }^{60} \mathrm{Co}$, $70 \mathrm{cGy} / \mathrm{min}$ ) at ambient temperature. Lymphocytes were stimulated to proliferate with PHA (final concentration of $1 \mu \mathrm{g} / \mathrm{ml}$ ). The flasks were incubated at $37^{\circ} \mathrm{C}$ (with $5 \% \mathrm{CO}_{2}$ ). Forty four hours later, cytochalasin B (Sigma) was added with a final concentration of $6 \mu \mathrm{g} / \mathrm{ml}$. After further incubation, cells were harvested at 92 hours post-stimulation by hypotonic shock with $0.075 \mathrm{M} \mathrm{KCl}$, followed by fixation, three times, in methanol/acetic acid (3:1) solution. Slides were stained in $2 \%$ Giemsa for $5 \mathrm{~min}$. Duplicate slides were made for each sample. For analysis, 500 binucleate cells (BNCs) per slide were scored for the number of micronucleus (MN) formation based on the international 
standard protocol [24]. In total, 1000 binucleate cells were scored per sample. The number of BNCs containing two or three MN was also recorded.

\section{Statistical analysis}

The data were analyzed using SPSS statistical software (version 17.0). For each participant, frequency and percentage of chromatid or chromosome type aberrations in 100 metaphases were calculated as well as micronuclei per thousand binucleate lymphocytes. For each sample, the spontaneous yield of each aberration obtained from the non-irradiated flask was subtracted from the yield in irradiated cells to get the net radio-induced chromosomal aberration yield. The total number of chromatid gaps and breaks per 100 metaphases was also determined to give a 'G2 score'. Different groups were compared using oneway ANOVA and unpaired $t$-test. Correlation between the $\mathrm{G}_{2}$ and the $\mathrm{G}_{0}$ - micronucleus assays was analyzed by Pearson correlation coefficient test.

\section{Results}

Thirty patients ( 21 males, 9 females) with mean age of $17.4 \pm 10.7$ years were evaluated. The mean age at onset and the mean age at diagnosis were $6.4 \pm 5.2$ and $11.7 \pm 9.3$ years, respectively (Table 1). The mean concentration of Igs (IgG: $175.8 \pm 165.3$; IgA: $14.5 \pm 21.4$; IgM: $20.6 \pm 16.5$; all in $\mu \mathrm{g} / \mathrm{dl}$ ) and CD marker percentages (CD3:69.6 \pm 17.5 ; CD4:30.8 \pm 12.7 ; CD8:38.6 \pm 11.9 ; CD19:13.39 \pm 4.3 ; all in $\%$ of lymphocytes) were recorded. The parents of twenty two patients $(73.3 \%)$ had consanguineous marriages. The mean G2 score for CVID patients $(81.2 \pm 19.6)$ was significantly higher than that for the healthy control group $(60.7 \pm 18.8, p=0.001)$ (Table 2). The mean frequency of micronucleus yield per 1000 binucleate cells in CVID patients $(71.4 \pm 24.6)$ was also significantly higher than that observed in healthy controls $(17.3 \pm 5.9, p=0.001)$ (Table 2). There was no significant difference in $\mathrm{G} 2$ score between first-degree relatives of CVID patients and healthy controls $(p=0.83)$, however there was a significant difference in micronucleus yield between CVID relatives and healthy controls (45.9 $\pm 19.6 v s .17 .3 \pm 5.9, p=0.001)$ (Table 2). The number of CVID patients with parental consanguinity was higher than the number of those with non-consanguineous parents (22 vs. 8), though, there was no significant difference between CVID patients with parental consanguinity versus cases from non-consanguineous parents in either G2- or G0- type aberrations (Mean G2 Score: $81.4 \pm 22.2$ vs. $80.6 \pm 10.1$; Mean micronuclei yield: $71.7 \pm 21.7$ vs. $70.5 \pm 32.9$ ). ALL patients showed more sensitivity to radiation by $\mathrm{G} 2$ score or micronucleus formation comparing to healthy controls ( $p=0.02, p=0.001$ respectively) (Table 2). There was no significant variation in G2 score or micronucleus yield between CVID patients and ALL cases. The correlation between $\mathrm{G} 2$ score and micronucleus yield in either CVID patients or in the healthy control group was not significant $(r=0.28, \mathrm{p}=0.12, r=0.27, p=0.14$, respectively, Fig. 2). More information about distribution and frequency of chromosomal aberrations for CVID patients and other groups are presented in Table 2. Further analysis fails to show any correlation between radiosensitivity and early or late onset of the disease or any type of clinical phenotyping.

\section{Discussion}

There are several primary immunodeficiency disorders particularly ataxia telangiectasia and ligase IV deficiency, which are susceptible to conventional doses of radiation therapy. Moreover, other genetic diseases including Nijmegen breakage syndrome, Mre11 deficiency, and Fanconi's anemia have been predictable for clinical radiosensitivity [25]. The higher incidence of chromosomal alterations after radiation has been demonstrated in the results of DNA repair deficiencies. Indeed, individuals with DNA repair deficiency may underlie the elevated cancer prevalence [26]. In this study we highlight chromosomal radiosensitivity in CVID patients with a greater sample size. We also recruit first-degree relatives of the patients to perceive their sensitivity in exposure to radiation compared with their affected child. In this investigation, radiation sensitivity was measured with both the $G_{2}$ and the $G_{0}$ - micronucleus assays to ensure presence or absence of radiosensitivity in the studied

Table 1. Characteristics of common variable immunodeficiency patients, their first-degree relatives and two different control groups of patients

\begin{tabular}{|c|c|c|c|c|c|}
\hline Group & Number & $\operatorname{Sex}(M / F)$ & Mean age (SD) & $\begin{array}{c}\text { Number of metaphases } \\
\text { examined }\end{array}$ & $\begin{array}{c}\text { Mean percentage of } \\
\text { aberrant metaphase (SD) }\end{array}$ \\
\hline Healthy controls & 30 & $21 / 9$ & $17.5(9.3)$ & 3000 & $15.6(13.9)$ \\
\hline CVID patients & 30 & $21 / 9$ & $17.4(10.7)$ & 3000 & $20.4(16.0)$ \\
\hline CVID relatives & 24 & $11 / 13$ & $42.0(14.6)$ & 2400 & $17.0(14.29)$ \\
\hline ALL patients & 20 & $18 / 2$ & $15.3(2.7)$ & 2000 & $29.2(23.2)$ \\
\hline AT patients & 6 & $2 / 4$ & $14.2(7.2)$ & 600 & $22.2(18.2)$ \\
\hline
\end{tabular}

CVID - common variable immunodeficiency, ALL - acute lymphocytic leukemia, AT - ataxia telangiectasia, SD - standard deviation 
Table 2. Details of $\mathrm{G}_{2}$ and $\mathrm{G}_{0}$ chromosomal aberration frequencies in irradiated peripheral blood lymphocytes of common variable immunodeficiency patients comparing with 4 different control groups

\begin{tabular}{|c|c|c|c|c|c|c|}
\hline Parameter & $\begin{array}{l}\text { Healthy controls } \\
\qquad(n=30)\end{array}$ & $\begin{array}{c}\text { CVID } \\
(n=30)\end{array}$ & $\begin{array}{c}\text { CVID-relatives } \\
\quad(n=24)\end{array}$ & $\begin{array}{c}\text { ALL } \\
(n=20)\end{array}$ & $\begin{array}{c}\text { AT } \\
(n=6)\end{array}$ & $p$-value ${ }^{\mathrm{a}}$ \\
\hline \multicolumn{7}{|l|}{ Chromatid breaks } \\
\hline Mean (SD) & $23.5(9.5)$ & $33.3(10.5)$ & $23.7(9.4)$ & $33.50(16.1)$ & $50.0(12.2)$ & 0.001 \\
\hline$p$-value ${ }^{\mathrm{b}}$ & - & $\begin{array}{c}\text { Healthy }(0.001) \\
\text { Relatives }(0.001) \\
\text { AT }(0.002)\end{array}$ & Healthy $(0.931)$ & $\begin{array}{c}\text { Healthy }(0.020) \\
\text { AT }(0.031)\end{array}$ & Healthy $(0.002)$ & - \\
\hline \multicolumn{7}{|l|}{ Chromatid gaps } \\
\hline Mean (SD) & $37.20(11.5)$ & $47.8(10.0)$ & $38.1(13.4)$ & $46.8(16.8)$ & $70.1(14.1)$ & 0.001 \\
\hline$p$-value ${ }^{\mathrm{b}}$ & - & $\begin{array}{c}\text { Healthy }(0.001) \\
\text { Relatives }(0.003) \\
\text { AT }(0.001)\end{array}$ & Healthy $(0.783)$ & $\begin{array}{l}\text { Healthy }(0.033) \\
\text { AT }(0.005)\end{array}$ & Healthy $(0.001)$ & - \\
\hline \multicolumn{7}{|c|}{ G2 score (chromatid breaks + chromatid gaps) } \\
\hline Mean (SD) & $60.7(18.8)$ & $81.2(19.6)$ & $61.8(21.6)$ & $80.3(32.6)$ & $120.2(21.7)$ & 0.001 \\
\hline$p$-value ${ }^{\mathrm{b}}$ & - & $\begin{array}{c}\text { Healthy }(0.001) \\
\text { Relatives }(0.001) \\
\text { AT }(0.001)\end{array}$ & Healthy (0.83) & $\begin{array}{c}\text { Healthy }(0.022) \\
\text { AT }(0.01)\end{array}$ & Healthy $(0.001)$ & - \\
\hline \multicolumn{7}{|c|}{ Chromosome breaks } \\
\hline Mean (SD) & $18.3(10.7)$ & $22.5(9.9)$ & $19.2(8.4)$ & $27.0(12.0)$ & $33.0(7.4)$ & 0.002 \\
\hline$p$-value ${ }^{\mathrm{b}}$ & - & $\begin{array}{c}\text { Healthy }(0.118) \\
\text { Relatives }(0.181) \\
\text { AT }(0.020)\end{array}$ & Healthy $(0.710)$ & $\begin{array}{l}\text { Healthy }(0.010) \\
\text { AT }(0.262)\end{array}$ & Healthy $(0.002)$ & - \\
\hline \multicolumn{7}{|l|}{ Chromosome gaps } \\
\hline Mean (SD) & $16.6(7.2)$ & $21.4(7.3)$ & $19.8(7.7)$ & $23.7(15.1)$ & $19.3(7.5)$ & 0.104 \\
\hline \multicolumn{7}{|l|}{ Fragmentations } \\
\hline Mean (SD) & $9.5(4.1)$ & $11.7(3.2)$ & $10.6(5.1)$ & $12.4(7.1)$ & $15.5(3.1)$ & 0.037 \\
\hline$p$-value ${ }^{\mathrm{b}}$ & - & $\begin{array}{c}\text { Healthy }(0.026) \\
\text { Relatives }(0.324) \\
\text { AT }(0.013)\end{array}$ & Healthy $(0.382)$ & $\begin{array}{c}\text { Healthy }(0.109) \\
\text { AT }(0.151)\end{array}$ & Healthy $(0.002)$ & - \\
\hline \multicolumn{7}{|l|}{ Exchange } \\
\hline Median $(\mathrm{IQR})^{\mathrm{c}}$ & $1(3-0)$ & $4(5.2-3)$ & $2(4.7-1)$ & $4(9.7-3)$ & $5(9-3.7)$ & - \\
\hline$p$-value ${ }^{\mathrm{b}}$ & - & - & - & - & - & - \\
\hline \multicolumn{7}{|l|}{ Micronucleus } \\
\hline Mean (SD) & $17.3(5.9)$ & $71.4(24.6)$ & $45.9(19.6)$ & $73.9(21.1)$ & $96.5(13.7)$ & 0.001 \\
\hline$p$-value ${ }^{\mathrm{b}}$ & - & $\begin{array}{c}\text { Healthy }(0.001) \\
\text { Relatives }(0.001) \\
\text { AT }(0.022)\end{array}$ & Healthy $(0.001)$ & $\begin{array}{c}\text { Healthy }(0.001) \\
\text { AT }(0.022)\end{array}$ & Healthy $(0.001)$ & - \\
\hline
\end{tabular}

individuals as the involved low penetrance genes in radiosensitivity in $\mathrm{G}_{0}$ and $\mathrm{G}_{2}$ stages of cell cycles are different.

In this study, the data showed that the mean G2 score and the mean frequency of micronucleus yield were significantly higher in CVID patients than those in healthy controls. There are few reports which indicate the evidence of radiosensitivity of DNA in CVID cases after exposure to radiation [27-29] or chemical agents [12] and its involvement with malignancy progress $[13,30,31]$. In our previous study we explained the dose-dependent chromosomal instability in CVID cases [27], however this property is not exhibited in other primary immunodeficiency syndromes [25]. Although, Vorechovskey et al. indicated the enhancement of chromosome damage in CVID cases, but they have 


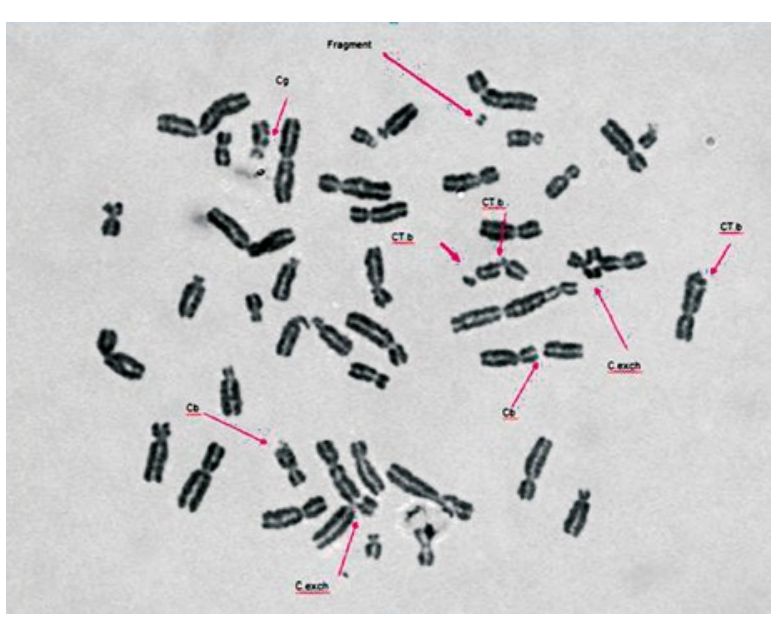

Fig. 1. Metaphase spread in peripheral blood lymphocytes after low dose rate $\gamma$-radiation exposure from a common variable immunodeficiency patient with a significant number of chromatid breaks, chromosome breaks and chromosome exchange noted. CT.b - chromatid break; $\mathrm{Cb}$ - chromosome break; Cg - chromosome gap; C.exch chromosome exchange

considered total aberrations per cell as an indicator of radiosensitivity and did not study each aberration separately [28]. However, in the present study, we evaluated both $\mathrm{G}_{2}$ chromosomal aberrations and G0-micronucleus formation to demonstrate radiosensitivity in CVID patients. This indicates that radiation in CVID patients potentially leads to elevation of chromosomal aberrations. Patients with CVID suffer from a number of infections, and therefore undergo frequent medical imaging that exposes them to radiation. Since these patients might be sensitive to radiation, they should be protected from unnecessary medical techniques that incorporate radiation.

Results of this study showed that first-degree relatives of CVID patients were radiosensitive with the micronucleus assay which showed a significant difference as compared with normal controls. As the genes involved in the processing of radiation induced DNA damage in G0 and G2 phases of the cell cycle are different $[32,33]$, therefore our results might point to the defects in genes involved in the processing of radiation-induced DNA damage of G0 phase in first-degree relatives of CVID patients. It is also reported that in breast cancer patients, chromosomal radiosensitivity is most evident using the micronucleus assay after exposure of lymphocytes with low dose rate radiation $[32,34]$.

The impact of these findings could be greatly improved by identifying the underlying genetic cause of the radiation sensitivity in CVID patients and potentially their first-degree relatives. Presumably not all CVID patients are radiation sensitive, since not all cases are due to disruption of DNA repair machinery, few cases might be due to receptor or downstream signaling dysfunction. It would also stand

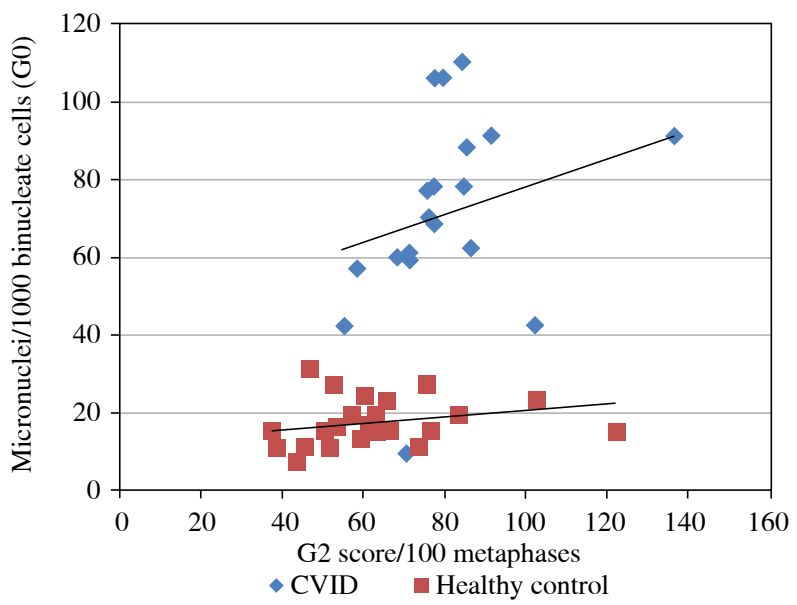

Fig. 2. Correlation between G2 score (chromatid breaks + chromatid gaps) and micronucleus yield in peripheral blood lymphocytes of common variable immunodeficiency (CVID) patients or of a healthy control group after low dose rate exposure of $\gamma$-irradiation. A poor correlation was found between the G2 and the G0 assays in both CVID patients and healthy control groups $(r=0.28, p=0.12$ and $r=0.27, p=0.14$, respectively)

to reason that not all family members carried risk variants for CVID. In surveys conducted in previous studies, we did not find a report on evaluation of radiosensitivity in first-degree relatives of CVID patients to compare our results with that. Altogether these findings support the theory of the autosomal recessive pattern of inheritance in selected cases with sensitivity to radiation [30]. Furthermore, we tried to compare the results of CVID patients and ALL cases to investigate chromosomal sensitivity of CVID patients compared with ALL as a malignancy originated from lymphocytes. We observed a higher frequency of G2 chromatid type aberrations and micronucleus yield in CVID as well as in ALL patients. It is reported that the frequency of chromosomal aberrations in ALL cases were statistically higher than that of normal controls, as stated that $65 \%$ of the ALL patients were sensitive to $\gamma$-irradiation $[35,36]$. Similar data between two groups indicate that high radiosensitivity in CVID may lead to later malignancies as our patients are mainly pediatric. An increased risk of cancer with an estimated incidence of 11-13\%, particularly during the 5th and 6th decade of life in CVID patients has been reported [37]. It has also been demonstrated that the frequency of chromatid breaks and gaps is higher in individuals with genetic conditions predisposing to cancer [38].

\section{Conclusions}

Our data showed that the same percentage of patients with ALL and CVID were sensitive to radiation, meaning that maximum care should be taken during their diagnosis or treatments with unnecessary medical techniques that in- 
corporate radiation. Furthermore, a homogenous group of patients with radiosensitivity may candidate for the same genetic defect involved in the upstream of class switching process. Further detailed investigations in CVID patients to characterize genome mutations or sites of double strand breaks are needed.

\section{Acknowledgements}

This research was supported by the Tehran University of Medical Sciences (grant no. 12853). The authors are very grateful to all the patients and their first-degree relatives for their kind collaboration in this study.

The authors declare no conflicts of interest.

\section{References}

1. Chapel H, Cunningham-Rundles C (2009): Update in understanding common variable immunodeficiency disorders (CVIDs) and the management of patients with these conditions. Br J Haematol 145: 709-727.

2. Chapel H, Lucas M, Lee M, et al. (2008): Common variable immunodeficiency disorders: division into distinct clinical phenotypes. Blood 112: 277-286.

3. Aghamohammadi A, Farhoudi A, Moin M, et al. (2005): Clinical and immunological features of 65 Iranian patients with common variable immunodeficiency. Clin Diagn Lab Immunol 12: 825-832.

4. Cunningham-Rundles C, Bodian C (1999): Common variable immunodeficiency: clinical and immunological features of 248 patients. Clin Immunol 92: 34-48.

5. Hermaszewski RA, Webster AD (1993): Primary hypogammaglobulinaemia: a survey of clinical manifestations and complications. Q J Med 86: 31-42.

6. Yazdani R, Hakemi MG, Sherkat R, et al. (2014): Genetic defects and the role of helper T-cells in the pathogenesis of common variable immunodeficiency. Adv Biomed Res 9: 2.

7. Azizi G, Abolhassani H, Asgardoon MH, et al. (2016): Autoimmunity in common variable immunodeficiency: epidemiology, pathophysiology and management. Expert Rev Clin Immunol 16: 1-15.

8. Pastorelli G, Roncarolo MG, Touraine JL, et al. (1989): Interleukin-4 suppresses immunoglobulin production by peripheral blood lymphocytes of patients with common variable immunodeficiency (CVI) induced by supernatants of $\mathrm{T}$ cell clones. Clin Exp Immunol 78: 341-347.

9. Sneller MC, Strober W (1990): Abnormalities of lymphokine gene expression in patients with common variable immunodeficiency. J Immunol 144: 3762-3769.

10. Kokron CM, Errante PR, Barros MT, et al. (2004): Clinical and laboratory aspects of common variable immunodeficiency. An Acad Bras Cienc 76: 707-726.

11. Vorechovsky I, Munzarova M, Lokaj J (1989): Increased bleomycin-induced chromosome damage in lymphocytes of patients with common variable immunodeficiency indicates an involvement of chromosomal instability in their cancer predisposition. Cancer Immunol Immunother 29: 303-306.
12. Vorechovsky I, Litzman J, Lokaj J, et al. (1990): Common variable immunodeficiency and malignancy: a report of two cases and possible explanation for the association. Cancer Immunol Immunother 31: 250-254.

13. Ahmad F, Dalvi R, Chavan D, et al. (2008): Cytogenetic profile of acute lymphocytic leukemia patients: report of a novel translocation $\mathrm{t}(4 ; 13)(\mathrm{q} 21 \times 3$; $\mathrm{q} 35)$ from an Indian population. Hematology 13: 28-33.

14. Somasundaram R, Prasad M, Ungerbäck J, et al. (2015): Transcription factor networks in B-cell differentiation link development to acute lymphoid leukemia. Blood 126: 144-152.

15. Chiaretti S, Foa R (2009): T-cell acute lymphoblastic leukemia. Haematologica 94: 160-162.

16. Ferrando AA, Look AT (eds.) (2000). Clinical implications of recurring chromosomal and associated molecular abnormalities in acute lymphoblastic leukemia. Seminars in hematology. Elsevier.

17. Aghamohammadi A, Mohammadinejad P, Abolhassani H, et al. (2014): Primary immunodeficiency disorders in Iran: update and new insights from the third report of the national registry. J Clin Immunol 34: 478-490.

18. Rezaei N, Aghamohammadi A, Moin M, et al. (2006): Frequency and clinical manifestations of patients with primary immunodeficiency disorders in Iran: update from the Iranian Primary Immunodeficiency Registry. J Clin Immunol 26: 519-532.

19. Conley ME, Notarangelo LD, Etzioni A (1999): Diagnostic criteria for primary immunodeficiencies. Representing PAGID (Pan-American Group for Immunodeficiency) and ESID (European Society for Immunodeficiencies). Clin Immunol 93: 190-197.

20. Picard C, Gaspar BH, Al-Herz W, et al. (2018): International Union of Immunological Societies: 2017 Primary Immunodeficiency Diseases Committee Report on Inborn Errors of Immunity. J Clin Immunol 38: 96-128.

21. West CM, Elyan SA, Berry P, et al. (1995): A comparison of the radiosensitivity of lymphocytes from normal donors, cancer patients, individuals with ataxia-telangiectasia (A-T) and A-T heterozygotes. Int J Radiat Biol 68: 197-203.

22. Scott D, Barber JB, Spreadborough AR, et al. (1999): Increased chromosomal radiosensitivity in breast cancer patients: a comparison of two assays. Int J Radiat Biol 75: 1-10.

23. Scott D, Barber JB, Levine EL, et al. (1998): Radiation-induced micronucleus induction in lymphocytes identifies a high frequency of radiosensitive cases among breast cancer patients: a test for predisposition? Br J Cancer 77: 614-620.

24. Fenech M, Chang WP, Kirsch-Volders M, et al. (2003): HUMN project: detailed description of the scoring criteria for the cytokinesis-block micronucleus assay using isolated human lymphocyte cultures. Mutat Res 534: 65-75.

25. Gatti RA (2001): The inherited basis of human radiosensitivity. Acta Oncologica 40: 702-711.

26. Zaki-Dizaji M, Akrami SM, Abolhassani H, et al. (2017): Ataxia telangiectasia syndrome: moonlighting ATM. Expert Rev Clin Immunol 13: 1155-1172.

27. Aghamohammadi A, Moin M, Kouhi A, et al. (2008): Chromosomal radiosensitivity in patients with common variable immunodeficiency. Immunobiology 213: 447-454.

28. Vorechovsky I, Scott D, Haeney MR, et al. (1993): Chromosomal radiosensitivity in common variable immune deficiency. Mutat Res 290: 255-264. 
29. Palanduz S, Palanduz A, Yalchin I (1998): In vitro chromosomal radiosensitivity in common variable immunodeficiency. Clin Immunol Immunopathol 86: 180-182.

30. Offer SM, Pan-Hammarström Q, Hammarström L, et al. (2010): Unique DNA repair gene variations and potential associations with the primary antibody deficiency syndromes IgAD and CVID. PLoS One 5: e12260.

31. Chua I, Quinti I, Grimbacher B (2008): Lymphoma in common variable immunodeficiency: interplay between immune dysregulation, infection and genetics. Curr Opin Hematol 15: 368-374.

32. Baeyens A, Thierens H, Claes K, et al. (2002): Chromosomal radiosensitivity in breast cancer patients with a known or putative genetic predisposition. Br J Cancer 87: 1379-1385.

33. Borgmann K, Haeberle D, Doerk T, et al. (2007): Genetic determination of chromosomal radiosensitivities in G0- and G2-phase human lymphocytes. Radiother Oncol 83: 196-202.

34. Mozdarani H, Mansouri Z, Haeri SA (2005): Cytogenetic radiosensitivity of g0-lymphocytes of breast and esophageal cancer patients as determined by micronucleus assay. J Radiat Res 46: 111-116.

35. Holt SM, Georgakilas AG (2007): Detection of complex DNA damage in gamma-irradiated acute lymphoblastic leukemia Pre-b NALM-6 cells. Radiat Res 168: 527-534.

36. Ramyar A, Aghamohammadi A, Mozdarani H, et al. (2011): Assessment of in vitro chromosomal sensitivity to low doses of gamma irradiation in patients with acute lymphoblastic leukemia. BCCR 2: 2-6.

37. López-Rocha E, Rodríguez-Mireles K, Segura-Méndez N, et al. (2015): [Malignancies in adult patients with common variable immunodeficiency]. Rev Alerg Mex 62: 22-27.

38. Sanford KK, Parshad R, Gantt R, et al. (1989): Factors affecting and significance of G2 chromatin radiosensitivity in predisposition to cancer. Int J Radiat Biol 55: 963-981. 